\title{
Using organisational memory in evaluations
}

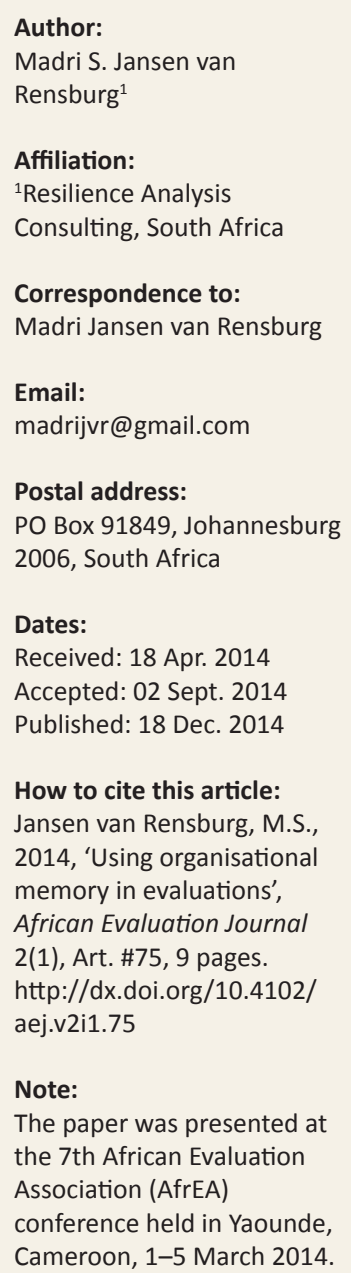

\section{Copyright:}

(C) 2014. The Authors.

Licensee: AOSIS

OpenJournals. This work is licensed under the Creative Commons Attribution License.
This article uses the case of a regional intermediary organisation to investigate organisational memory $(\mathrm{OM})$ and its contribution to knowledge management and activities in evaluations. Understanding of, and accessing $\mathrm{OM}$ is critical for participatory evaluations. The aim of the article is to reflect on the OM of a non-governmental organisation (NGO) and what implications the structural changes in OM over the organisation's life cycle have for evaluators. It further aims to advocate an awareness of OM and explains how evaluators can access and utilise it more effectively. Evaluators need to have an understanding of $\mathrm{OM}$, and to take more responsibility for disseminating results to enhance it. This case study reflects on a retrospective case example of a regional NGO. The report reflects the development and structure of the life cycle of the organisation. The data collection included in-depth interviews with staff members and other key stakeholders, engagement with beneficiary organisations and donors, and analyses of documents, electronic files and audio-visual material. Since OM survives after the demise of an organisation, and is accessible through directories, it is important for the evaluator to include historical information. Specific implications for evaluators include the ability to access OM through directories and networks of the organisation. As evaluators hold $\mathrm{OM}$ of all the organisations they have engaged with, they also have a responsibility to share knowledge. The key findings of this study illustrate the importance of accessing the memory and historical information of the organisation. Understanding OM enhances the in-depth comprehension of the activity, project or programme under investigation, and the collective knowledge generated as a result of it.

Cet article évoque le cas d'une organisation régionale intermédiaire enquêtant sur la Mémoire Organisationnelle $(\mathrm{MO})$ et sa contribution à la gestion des connaissances et aux activités dans les évaluations. La compréhension et l'accès à la Mémoire Organisationnelle (MO) sont essentiels aux évaluations participatives. L'objectif de l'article est de réfléchir à la MO d'une organisation non-gouvernementale $(\mathrm{ONG})$ et des implications que les changements structurels dans la $\mathrm{MO}$ pendant le cycle de vie de l'organisation ont sur les évaluateurs. Il vise en outre à préconiser une sensibilisation à l'OM et explique comment les évaluateurs peuvent y accéder et l'utiliser plus efficacement. Les évaluateurs doivent comprendre l'OM, et assumer davantage de responsabilités pour diffuser des résultats afin de l'améliorer. Cette étude de cas se penche sur un exemple de cas rétrospectif d'une ONG régionale. Le rapport apporte une réflexion sur l'évolution et la structure du cycle de vie de l'organisation. La collecte de données incluait des entretiens en profondeur avec des membres du personnel et d'autres intervenants clés, l'implication d'organisations et de donateurs bénéficiaires, et des analyses de documents, de fichiers électroniques et de matériel audiovisuel. Puisque la MO survit après la disparition d'une organisation, et est accessible à travers les répertoires, il est important pour l'évaluateur d'inclure des informations sur l'historique. Les implications spécifiques pour les évaluateurs comprennent la possibilité d'accéder à la MO à travers les répertoires et les réseaux de l'organisation. Puisque les évaluateurs détiennent la MO de toutes les organisations dans lesquelles ils se sont impliqués, ils ont aussi la responsabilité de partager leurs connaissances. Les principaux résultats de cette étude illustrent l'importance de l'accès à la mémoire et de l'information historique de l'organisation. Comprendre la MO améliore la compréhension en profondeur de l'activité, d'un projet ou d'un programme visé par l'enquête, et la connaissance collective générée à la suite de celui-ci.

\section{Introduction}

For organisations to survive in changing environments, they need to learn from past experiences, which will enable optimal decision-making. Organisational practice is influenced by organisational learning, in that an organisation needs information to adjust the implementation of its programmes and policies, so as to deliver against objectives. Part of the 


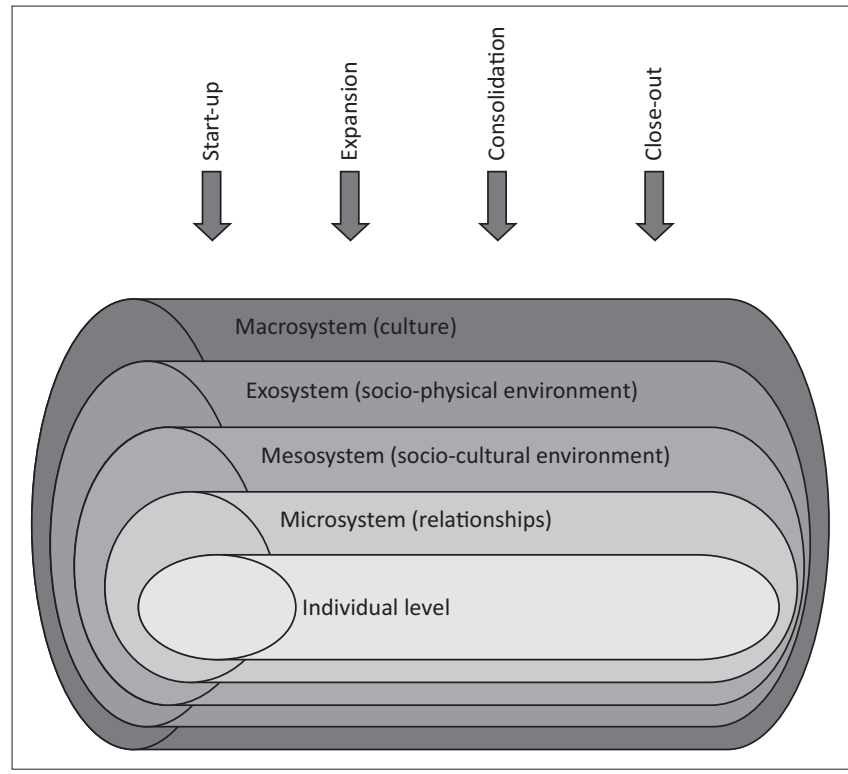

FIGURE 1: Knowledge hierarchy (adapted from Britton 2005:44).

use of knowledge is sharing relevant information with all stakeholders (Carroll \& Montgomery 1987).

Most evaluations are geared toward improving organisational practice and enhancing organisational learning (Preskill \& Torres 2004; Russ-Eft \& Preskill 2009; USAID 2011). Evaluation is essentially about accountability and learning and, therefore, requires valid, reliable and trustworthy information to make judgements and influence learning. This is important in participatory evaluations and evaluations that focus on wider stakeholder engagement (Cousins \& Earl 1992). Organisational memory is defined as 'the means by which knowledge from the past is brought to bear on present activities, thus resulting in higher or lower levels of organisational effectiveness' (Stein 1995). Understanding the value of shared $\mathrm{OM}$ is also important when disseminating information for learning within the organisation and wider interest groups such as the scientific community, governments, and global development organisations (OECD 2001; USAID 2011).

According to Britton (2005) knowledge management and learning involves working with data, information, knowledge, intelligence and wisdom involved in a hierarchical manner (see Figure 1). Evaluators generally work with data and information, but should ultimately be responsible for knowledge, as that is the level that is used for decision-making by projects and donors. Unlike many evaluators who limit themselves to the interpretation of the scattered data collected in the field, without consulting their clients on contextual factors and possible data anomalies, enlightened evaluators are particularly concerned with the organisations' level of knowledge, intelligence and wisdom (Tarsilla 2010).

A sound knowledge management system is critical to capture essential- and often dismissed - aspects of any organisation's life. Accordingly, for knowledge management to take OM into account, the utility of the evaluation findings will be far greater thanks to a better contextualisation of the collected data.

Organisational learning is important in evaluation, especially for participatory approaches that are based on the understanding that knowledge is socially constructed and that memory is formed and shared by members in the system (Cousins \& Earl 1992). An understanding of the OM is critical for many activities in the evaluation process, from accessing organisational knowledge to sharing that knowledge with a wider and more influential audience. Organisational memory (OM) does not only contain the information of an organisation, but also, and more importantly, the knowledge it generated throughout its lifetime. Accessing such information is important when making judgements about effectiveness, efficiency, relevance, sustainability and impact. The OM contains explanations of changes over time - a history of the reactions of the system (organisation) to internal and external factors, including policy influences and changes. Through the directory of OM that enables a user to access different containers (aspects) of the OM, the lessons learned by, and in association with, other organisations can also be retrieved. The directory of $\mathrm{OM}$ is the central part of the memory that holds information on where to find different parts of it.

This is similar to the index system of a library that can direct a person to a specific source of information. For example a person in the organisation has insight into what bits of information or areas of expertise past colleagues worked with. Information can then be traced from these sources. Understanding OM enables the evaluator to engage more meaningfully with the organisation(s), the commissioner of the evaluation, international development organisations and policy makers. This understanding of OM helps the evaluator to explore, collate, incorporate and manage information that enhances the use and dissemination of the generated knowledge.

OM consists of both explicit (as expressed in policies and documents) and tacit (insight and skills embedded in individuals) memory (Connell, Klein \& Powell 2003). Stein (1995) distinguishes four types of OM, combining explicit and tacit memory and individual and social memory. The four types are conscious (explicit individual), automatic (implicit individual), objectified (explicit social) and collective (implicit social) memory. Walsh and Ungson (1991) described $\mathrm{OM}$ as consisting of five storage bins, namely individuals, organisational culture, processes of transformation, organisational structures (roles) and workplace ecology. The different processes of OM include acquisition, retention, retrieval and maintenance (prevention of loss and decay of memory) of information (Stein 1995; Walsh \& Ungson 1991). The biological approach uses human memory as a metaphor for OM(Hall 2005). The current focus and application is mostly concerned with information technologies for automating and supporting OM, so as to enhance organisational performance (Connell, Klein \& Powell 2003; Corbett 2000). 


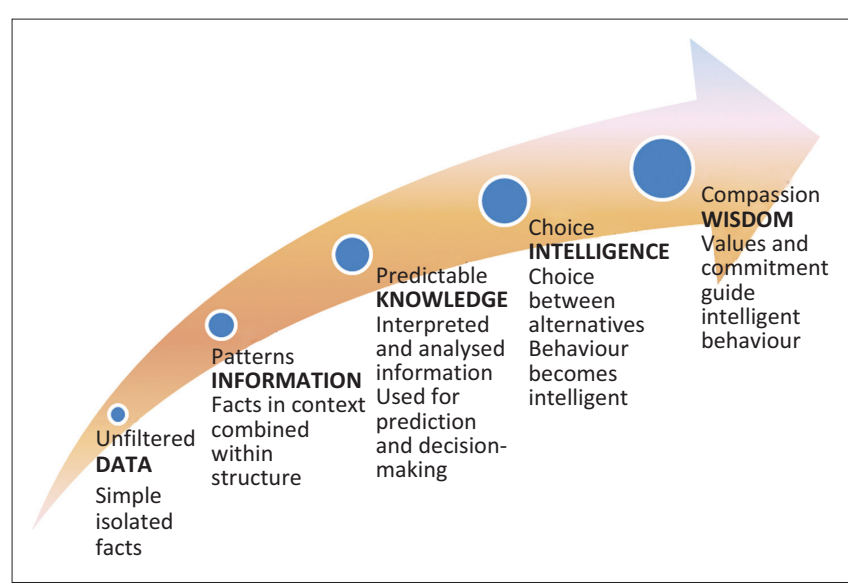

FIGURE 2: Ecological model of organisation development.

Previous research investigated the structure of $\mathrm{OM}$ and provided cross-sectional views thereof, as if $\mathrm{OM}$ was static and changes over time had little importance. To fully understand and use OM effectively, a temporal approach (focusing on different developmental stages of an organisation) is needed. In the case of the organisation discussed in this article the following phases were identified: start-up; expansion in target area and functions; and consolidation and close down (partial or full, with a resulting setback or decline).

Although great emphasis is placed on learning for organisations, little emphasis has been placed, or research carried out, on the importance of OM for evaluations. The objective of this article is to highlight the importance of an understanding of $\mathrm{OM}$ for evaluators of development programmes and organisations by describing the structure of OM throughout the life cycle of the case example. An indepth review of the OM of an NGO that completed all the developmental phases was conducted to understand the structure of the OM from the perspectives of the organisation, previous staff members, beneficiary organisations and key stakeholders (Jansen van Rensburg 2011a). The current reflection, which could enhance evaluators' understanding of $\mathrm{OM}$, focuses specifically on the implications that the findings of the case had.

The case example is described, firstly, by looking at the development of OM through the different life cycle phases of the organisation. This is followed by a description of the components or subsystems of OM (focusing on those relevant for evaluators) using an ecological framework (McNamara 2006). The following levels were included in the ecological model:

- Individual.

- Interpersonal processes and primary groups with formal and informal social network and support systems.

- Institutional factors (i.e. norms, culture, structures, rules and regulations).

- Community factors, such as relationships amongst institutions and organisations, and informal networks within defined boundaries (i.e. area economics, media, community services, neighbourhood organisations, formal and informal leadership).
- Culture at large (developmental sector, regional laws and policies, political stability, and global aspects).

Figure 2 illustrates the ecological model and the different phases of the development of the organisation (Jansen van Rensburg 2004).

\section{Research design}

This article comprised a single, in-depth, explanatory, historical case study of $\mathrm{OM}$ in an organisation that completed all development phases, from start-up to close down (Al-Talil 2004; Edwards \& Fowler 2002). The case used in this article was a regional NGO working in HIV prevention and mitigation, and included investigation of its OM throughout the 23 years that the organisation existed (Jansen van Rensburg 2011a).

Project Support Group (PSG) grew from a local NGO to an intermediary NGO, working in nine Southern African Development Community (SADC) countries at its closure in 2008. PSG was involved in obtaining and managing funds from large international donors, and coordinating the efforts of 42 partner organisations to benefit grass rootslevel communities. Being able to investigate the OM of this organisation provided a unique opportunity to study its development and characteristics throughout the life cycle stages of the organisation, from starting up to closing down, through stages of expansion (both in physical target, territory and function) and consolidation. The researcher was authorised by PSG to conduct the study before its closure by the PSG management and board. Participation in all interviews (during and after closure) was voluntary and included verbal or written informed consent.

A complex dataset was used, representing the entire lifespan of the organisation. Data source triangulation included the following sources of evidence:

- Documentation and archival reviews.

- Forty-seven interviews with employees.

- Engagement with 42 NGOs and CBOs in nine different countries.

- Interviews with representatives of similar organisations, a founder member and service providers and consultants.

- Direct observations during site visits that included contextual reality observations, participant observations during meetings and training sessions.

- Physical artefacts, including observation of explicit memory in hard copies and electronic documents and files during various site visits.

In order to enhance information gathering, a variety of interview methods were used (including face to face, telephonic and electronic interviews), so as to include staff who had emigrated and beneficiaries in other Southern African countries. Some of the face-to-face interviews were conducted in Bulawayo, Zimbabwe, and others in South Africa. Different tools were developed for the different types of stakeholders. 
The trustworthiness of the interpretations and conclusions was tested by various means, including using key informant review analysis. Triangulation of multiple information sources (including different perspectives of not only previous and current staff members, but also beneficiary and donor organisations), methods (interviews, structured self-completion questionnaires, document review, etc.), and interpretations (using different researchers and testing convergence of the themes) enhanced the information set and strengthened the conclusions (Ammenwerth, Iller \& Mansmann 2003; Patton 2002; Stake 1995). Because of the complexity of the data sources and the integrated approach of analysis and interpretation, the results and discussion are presented as one section for ease of understanding. Specific reference to, and more information about, each data source as it relates to each aspect presented here is available from the author in the more comprehensive case description document (Jansen van Rensburg 2011a).

\section{Results and discussion Description of PSG}

The case used in this article was a regional NGO working in HIV prevention and mitigation. PSG was established in 1985, in association with the Department of Psychology at the University of Zimbabwe, to work in HIV prevention and behaviour change. This work also intended to incorporate research and accurate data collection. PSG was the brainchild of Professor David Wilson, who was not only passionate about preventing the HIV epidemic, but also believed it was critical to focus on collecting accurate and useful information. The organisation grew from being a local NGO in Bulawayo (with three staff members), to expanding locally in Zimbabwe, and then regionally to, first, Zambia and, later, Malawi, Mozambique, Namibia, South Africa, Swaziland, Botswana and Lesotho. PSG provided funding and technical support to various partner NGOs and CBOs in these countries. Not only the staff complement, but also the number of partner organisation numbers increased as the organisation expanded its functions (including mitigation) and target areas. Different organisational structures were in place during the different phases, but, generally, PSG maintained a relatively flat hierarchical staff structure. During the later phases of the organisation, its partner organisations (some of which also expanded their territory to include different countries) were hierarchically arranged into core partners, called anchor partners, that supported smaller and/or younger organisations. PSG closed down during 2008 after a decrease in funding of regional initiatives limited the number of regional NGOs in Southern Africa. A small staff complement was given the mandate of closing the organisation down in a structured manner. At the closure of PSG - and, from investigations, more than a year after its closure - all 42 partner organisations continued existing, making PSG's activities and influence sustainable through the daughter organisations.

\section{Development of OM}

From the analysis and integration of the data, it is clear that OM changed significantly through the different phases of the organisation's development. It is important to be aware that $\mathrm{OM}$ is not a stable entity, but that it changes and evolves over time. The OM is part of the organisation, but also has its own development and existence separate from the organisation. For example, OM continues to exist after the demise of the organisation itself. This section describes the development of the OM of PSG. Implications for evaluators and considerations for evaluations are given for each organisational development phase. It is advisable that evaluators should be aware that, when conducting an evaluation, the relevant phase or phases of the development of OM should be accessed.

\section{OM during the start-up of PSG}

The OM originated in the vision and mission of PSG. This early version (foundation or historical component) of OM enabled initial learning of the organisation and the development of strategies that guided the organisation's start-up. The OM involved much more than simply containing the history of the organisation: it was actively filtering and sorting historical events and integrating information, so as to make adjustments to future activities. For example, the focus of PSG was on reducing sexually transmitted infections (STIs), including accurate surveillance. This initial work was well-documented and the results achieved allowed the organisation to obtain not only consultancy work, but funding. This meticulous documentation of strategy, activities, data and results, and reports, had far-reaching implications for the organisation, its partners and the beneficiaries. The fact that PSG could build a reputation for itself and its partners remained one of the key factors till the organisation closed, and was mentioned as one of the most important aspects for the survival of its partner organisations. The OM of the start-up phase also allowed replication of PSG's work to include sex workers and truck drivers in other areas with highly mobile communities.

The main driver of OM was the founder of PSG - the person who was influential in determining the vision, mission and strategy. The $\mathrm{OM}$ at this stage relied on the relationships created with donors, civil society, government structures and other partners. With a very small staff complement, the OM during this phase was shared amongst all individuals, and documentation took priority.

For an evaluator it would be important to obtain information from the main driver of the OM who is in most organisations probably the founder. Understanding the basis of OM allows the evaluator to understand the goals of the organisation, how and why it started and how it adjusted and refined its strategy according to successes and failures. This understanding is needed to guide further evaluation data collection and to enable understanding of the significant contributions the organisation, programme or project made in line with its original goals.

\section{OM changes with expansion of the organisation}

During the expansion of the organisation, the OM was still situated in key staff members. For example, the management 
of the physical documents and archives was the responsibility of the financial manager. The partner organisations started to develop their own OM (based on replication of the mother organisation, PSG's, OM development process) and housed parts of the mother organisation's OM. This expansion of $\mathrm{OM}$ was vital, not only with regard to the management of documents, but also for the new capacity and the expansion of skills across the region. During the expansion phase $\mathrm{OM}$ was still situated in the individual staff members and the founder of the organisation. There was no threat of memory loss whilst expanding, but the expansion of the organisation across country borders raised many challenges. The PSG head office was now situated in South Africa (as it was moved because of the political situation in Zimbabwe) with other offices in Zambia and Zimbabwe. Early in this developmental phase, there were electronic backups of the documents (scanned and stored by the founder), but most of these were lost during the move from Zimbabwe to South Africa. Publications (scientific articles and annual and other reports) that were not lost as they were in the public domain, revealed stable aspects of the memory, whilst the rest of the memory was situated in individuals, partner organisations and donors. This illustrates the importance of sharing OM with different audiences and in different formats.

Individual OM continued to play a major role during the phase of expansion of function and activities. The OM was now the responsibility of the managers of the different departments, who were not only supposed to champion the development of the OM, but also to manage it. Induction of new staff to the organisation, especially orientating them on how the vision relates to the history and current activities of the organisation, was critical to enable new staff to carry OM. The core components of OM during this phase included:

- Documents.

- The vision and clear communication of the vision.

- Strategic plans and documents, and project proposals.

- Reports on past achievements (as expressed in financial and narrative reports to donors) and reflection on failures to achieve success.

- The history of the organisation (including descriptions of activities).

- Correspondence with all stakeholders, especially revealing relationships.

- Networks.

- Individuals (in this phase strongly related to key influential persons and those carrying the historical aspects of the memory).

- Partner organisations.

- Beneficiaries.

A major development in the later part of this phase was the documentation of procedures and policies. It revealed a very structured, formal and, perhaps, rigid organisational management style and OM.

For evaluators, it is important to understand that, in this stage, $\mathrm{OM}$ is still being developed and might be situated in other partner organisations and different individuals, and in tacit and explicit forms. The OM is also linked to the initial vision of the organisation. Care should be taken to access all aspects of $\mathrm{OM}$ and not only rely on documentation.

\section{OM during the consolidation of PSG}

The staff complement was now large with different departments, including, amongst others, management, finance, operations and projects, and research. The activities, and increased financial resources allocated to maintain the $\mathrm{OM}$ during the consolidation phase were focused on the development of a sophisticated management information system (MIS). The MIS was supposed to provide an electronic filing system for managing information in the organisation. The MIS was (incorrectly) considered to equate to OM. The actual OM during this phase was spread over all departments and amongst all individuals, each holding a portion of the $\mathrm{OM}$. The tacit memory (hard copies of documents; electronic copies, including backups on the server; and multimedia of PSG and partner organisations, such as DVDs, videos and audio cassettes) was well developed and managed by a dedicated person. There was also a strong dependence on individuals as directories (metamemory) of the OM, with key persons knowing where to access different aspects of the memory (whether internal to the organisation or outside in partner organisations, past staff members, publications, or other stakeholders). The importance of the metamemory was also evident from the continued involvement of past staff members and the reliance on their memories (and directories) of where documents were located (although the filing system was accessible and categorised). During this phase, it was recognised that OM also resided within PSG's partner organisations (through information documented and used as lessons learned and good practices). This not only strengthened the mother organisation's OM, but also the OM of the partner organisations.

Evaluators would probably find it easy to access the explicit $\mathrm{OM}$ during this phase, but in doing so might run the risk of not accessing the very important part of the memory situated outside the organisation. As it is likely that many evaluation studies will be commissioned during this developmental phase of the organisation, the role and responsibility of the evaluator also increases. Other evaluations are a valuable source of information, and knowledge generated through previous evaluations, and organisational reactions to the results, is an important source of information for any evaluator. The OM is not only evident in formal reports, but the evaluators commissioned and involved in the evaluations are also carriers of the OM. Any evaluator will carry a portion of the $\mathrm{OM}$, as the evaluator role encompasses being both a critic and a facilitator of learning, during and after an evaluation activity.

Most evaluators are not aware of the important information source that other evaluators can be in accessing OM, often explaining the 'how' of findings. They are unfamiliar with the 
directories or the use of these indexes to obtain information from the OM. In general evaluators are also unaware of their own responsibility and role in maintaining and sharing OM and, more importantly, the implications and knowledge generated through their work. Evaluators carry OM both on an individual evaluation study level (holding OM after an evaluation), and as key role players in integrating results from different evaluations. For example, it would be important to access OM carried by previous evaluators (or at least be able to access more hidden parts of $\mathrm{OM}$ ), to be aware of the OM carried by oneself, and to integrate knowledge from different evaluations. The wealth of information that lies with evaluators on specific topics, for example girls' education in different contexts, is mostly overlooked and OM carried by evaluators too often disregarded (Tarsilla 2010).

\section{OM and the closing of PSG}

During the close down phase, most of the OM was found in individuals who had already left the organisation and through the directories of those who remained to close down the organisation, including the executive director, finance manager and two junior staff members. In general, OM was regarded as healthy and strong. The $\mathrm{OM}$ is an entity that stands alone from the organisation or the staff; it needs to continue beyond infinity, beyond any human lifespan or the corporate dynasty. It can adapt and is, therefore, sustainable.

It was stated by a PSG staff member that the OM is 'not only in books, but like a family business relying on feelings and emotions'. The memory was elicited by strong emotions, such as relating events to anger or sadness, illustrating the complete integration of $\mathrm{OM}$ with the individuals carrying it. The high turnover of management and poor handover of information, especially between rapidly replaced executive directors, seriously inhibited the memory from functioning optimally. The general lack of proper communication internally in the organisation was also perceived as a major negative influence. The deletion of a major component of the MIS by a disgruntled staff member continued to influence OM negatively during this phase. Yet OM was never deleted, even after the organisation permanently closed, and the tacit memory was placed in storage with one of the partner organisations.

The most important implication of the findings about OM during the close down phase of PSG was that OM exists even after the organisation no longer does. This finding has important implications for meta-evaluations, or evaluations that include a large number of programmes or projects. The finding that $\mathrm{OM}$ remains available means that evaluations could, and should, include data, information, knowledge and wisdom from all organisations, irrespective of whether they still exist or not. This could have far-reaching implications for policy decisions and influences. By gaining access to the directories of an organisation, additional valuable information can be included, and a better understanding gained, about any intervention.

\section{Factors influencing OM structure and function}

The factors of importance to evaluators and in evaluations that influence $\mathrm{OM}$ were analysed using the different ecological systems: individual level; interpersonal processes, social network and support systems; institutional factors; community factors, relationships and networks; and global factors. These factors changed over the existence of the organisation and its OM. Table 1 presents a matrix of the intersection between the timing of the events and the different levels and systems of the ecological framework.

\section{Individual to collective memory}

The function of intellectual interpretation of information and generation of new knowledge depends largely on individual OM. Individual characteristics of employees (personality type, academic inclination, preference to document information and emotional reactions) influenced $\mathrm{OM}$, as was also observed by Jashapara (2007) and Searle (1999).

There was a shift in the perceived importance of different individual OMs. During the start-up phase, the founder was the most critical person. During expansion into a larger target area, all individuals (especially since it was a small, core group of two to three individuals) held the OM collectively. When functions expanded, and the staff complement increased, the OM was perceived to be managed by the unit managers of the organisation. During consolidation, the memory was perceived to be located in all staff members, with recognition of the important need to identify relevant directories (Jansen van Rensburg 2011b). During the last two phases of the consolidation and close down of the organisation, the focus shifted to metamemory and directories (and supra-directories of the directories). Individual networks now formed the basis of the memory.

In the African context this is an important aspect to remember as the interplay between what is considered individual

TABLE 1: Summary of key main findings.

\begin{tabular}{|c|c|c|c|c|c|}
\hline Level & Start-up & Expand area & Expand function & Consolidate & Close down \\
\hline Individual & Founder & Key staff passion & Staff diversity & High staff turnover & Ex-staff. \\
\hline Micro & Small group & Close relationships & Staff dynamics & MIS system & External directories. \\
\hline Meso & Vision (theory of change) & Financial structures & Policies \& procedures & Changes to governance & 'Lead to close' vision. \\
\hline Exo & $\begin{array}{l}\text { Direct involvement with } \\
\text { each partner }\end{array}$ & $\begin{array}{l}\text { Increase in partners } \\
\text { (based on relationships) }\end{array}$ & $\begin{array}{l}\text { IOR and networks and } \\
\text { reputation }\end{array}$ & Management handover & $\begin{array}{l}\text { Development of } \\
\text { promotional material for } \\
\text { partner sustainability. }\end{array}$ \\
\hline Macro & Local needs & Political change & Regional influence & Global influence & $\begin{array}{l}\text { Beneficiaries and partners } \\
\text { impact promotion. }\end{array}$ \\
\hline
\end{tabular}


memory and what is shared as OM can have different meanings. What is openly declared as OM might not include the bits of memory situated in individuals. The OM housed in individuals needs to be accessed and the evaluator needs to search wider for relevant OM.

\section{Storage of OM}

One would expect electronic information technology to be of primary benefit to the development of OM. Obtaining documents and information from the early phase was easier than anticipated, given that the physical documents were mostly destroyed during the turmoil in Zimbabwe and few electronic copies were available. Paradoxically, these documents, for example annual reports, were more easily recovered from donors than documents developed later in the organisation's lifespan, and mostly sent electronically. Physical documents were more likely to be filed in an accessible and more 'public' space than electronic copies that were mostly only shared with a relative small audience directly involved with the organisation. It was easier to obtain reports than proposals, even when they were directly linked and had financial contractual value. Later documents, including proposals, often contained valuable information on the history and successes of the organisation, whilst narrative reports to donors contained information regarding challenges and solutions. This information seemed to be more refined and integrated than mere documentation of events and activities.

The MIS system is often (wrongly) regarded as the OM of an organisation. For instance, Watson (2006) saw data management and OM tasks as synonymous. However, Burn and Ash (2000) and Schwartz, Divitini and Brasethvik (2000) shared the opinion, based on the results of the current study, that MIS is useful as a capturing tool, but should not be considered as encompassing the $\mathrm{OM}$, especially considering the importance of individuals and individual OM (Anand, Manz \& Glick 1998). The MIS can be used to fulfil certain functions, for example retrieval and access, but it is not OM, merely one component of it. Two main contributions of a MIS are: making knowledge accessible, and making directories to knowledge accessible (Hamidi \& Jusoff 2009, Jansen van Rensburg 2011b). It is important also to view technological development as a macro system factor. Given the rate of present technological advances, international and global issues are increasingly influencing even small NGOs, and events in remote or rural areas in African countries can have far-reaching implications for the storing and recall of OM.

\section{Accessing OM}

Probably the most important factors that can be managed when studying OM - and which should receive more attention when doing evaluations - are the directories of the organisation (Girard 2009; Hamidi \& Jusoff 2009; Jansen van Rensburg 2011b; Nevo \& Wand 2005). Accessing OM is virtually impossible without directories (Anand, Manz \& Glick 1998). The existence of directories enables access to the networks (and individual and inter-organisational relationships) and OM stored in individual memories (and existing hard copies). This not only has implications for investment in sophisticated technology, but for the need for 'soft' interpersonal skills in building and maintaining important relationships with key gatekeepers and those holding the metamemory and directories. Understanding the importance of key individuals in an organisation's network that gives access to $\mathrm{OM}$ is critical for evaluators and they should be competent in interpersonal skills.

\section{Organisational influences on OM}

The use of audio-visual aids to capture and access $\mathrm{OM}$ is important. These aids illustrate activities taking place, as well as the impact of the activities. Audio-visual aids also strengthen the development of mental cues in individual OMs that simplify the retrieval of details (Baddeley 1998). Narratives often form an important aspect of evaluation strategies and methodologies in the African context. These should not only be used to collect information, but also to access the OM.

Whilst the organisation is growing and expanding, the influence of the leadership (often visionary in the start-up phases) is very direct. During the close down phase of this case study, the same type of visionary leadership was needed to enable planning and executing the closure in a manner that retained $\mathrm{OM}$.

The vision of the NGO seemed to play a crucial role in the case under study throughout the development of the organisation. The OM was not only expressed through the vision, but the vision guided its development and perceived importance.

A theory of change, and the results chain, forms the blueprint of the organisation and describes, in a logical manner, the consecutive steps that need to be taken to achieve the overall vision, with all the drivers and processes needed to achieve consecutive results (Funnell \& Rogers 2011). The theory of change of PSG was explicit throughout the different phases and shared by everyone interviewed for this article. It took into account the environment and stakeholders, such as donors and beneficiaries. The theory of change was prominently expressed through OM.

\section{The influence of organisational culture}

The following were the main aspects of the culture of the organisation that were expressed by and influenced its OM. Learning in the organisation and decision-making abilities were strongly influenced by OM. The more the organisation learned from its past successes and failures, the more accurately it could apply this knowledge in decision-making processes and strategies. There was also learning taking place between PSG and its partners. Not only did they share facets of $\mathrm{OM}$, and replicate aspects of the OM process, but the partner experiences were incorporated into OM development of PSG. 
When communication was open and processes transparent, OM was easily shared. This confirms the studies by Krippendorff (1975) and Stein (1989, 1995). Inhibited communication between staff and the board and donors hampered the exchanges in the development of OM. This is also important for evaluators who are trying to access OM during evaluations, and having to balance demands from donors with organisational intentions.

Information and knowledge generated in OM was disseminated between staff, to partner organisations and to the wider scientific community through conference presentations and scientific publications throughout the life of the organisation. This was a major positive influence on preserving the memory. A culture of trust, transparency and openness enabled the environment to encourage contributions from all staff to the development of OM. It enables a culture of sharing of information (Levin \& Cross 2004).

The environment should be conducive to documenting and record keeping. This should be mainstreamed into all aspects of the organisation and all staff members should be involved. The documentation should be complete, accurate and relevant and, to ensure this, responsibility for the overall management of OM should lie with a person with enough authority. The documentation and responsibility of its maintenance at PSG shifted during the different phases. The functionality and health of the record keeping of the organisation remained intact as long as the directories to access the documents were available (even after the organisation closed down).

One of the key aspects that could enhance OM is the opportunity to reflect on and to integrate information (Schoeneborn \& Blaschke 2009). During the different phases of PSG's development, team building and other opportunities for reflection contributed to the integration of OM. The various regional workshops attended by all PSG beneficiary organisations also contributed to reflection as a larger organisation and allowed each individual organisation the opportunity to integrate their own information. This is even more important in fast-evolving organisations (Roth \& Kleiner 1998; Sauvagnac \& Falzon 2003; Sparrow 1999). These reflective events also assisted in unlearning (the active and conscious activities to change certain learned behaviours which is needed to ensure that negative or unproductive behaviours are not repeated), and forgetting (deleting certain information from the memory), as forming important parts of the OM process, especially during times of rapid change, such as the expansion of PSG regionally (Akgün et al. 2007; Baddeley 1998; Henderson 1996; Schoeneborn \& Blaschke 2009).

\section{The importance of networks and relationships}

Internal (general OM and individual OMs of management and staff) and external (donors, beneficiaries, evaluators and ex-staff) role players are all important for OM. The implication is that good relationships and networks are important, especially relationships amongst partner organisations (Stein 1989). The networking abilities of the organisation increased with better access to the combined OM (and especially the directories and metamemory) of PSG, its partners, beneficiaries and stakeholders. Inter-organisational networks were very important for regional and intermediary organisations such as PSG, as their main function was to increase the combined impact of the grass roots organisations which are best suited for community responses. Using relationships and networks are impossible without an OM, and access to a metamemory is difficult without documented relationships and the mapping of relevant networks. Accessing the networks and directories is critical for any evaluator (Jansen van Rensburg 2011b).

\section{Impact of OM}

One of the main insights gained regarding the value of the OM of PSG as a regional intermediary organisation, was that it allowed the organisation's partner organisations to adapt to the changing environment and become more sustainable. Kurtyka $(2005,2009)$ placed a similar emphasis on environmental factors. Major changes in the environment, including the political and socio-economic situation in Zimbabwe and the resulting exodus of NGOs, especially larger and regional intermediary organisations (including PSG), along with the consequences of the situation, had an impact on the maintenance and development of the OM. These socio-economic influences are integral to the composition of OMs and received attention from authors such as Curry, Hassouneh-Phillips and Johnston-Silverberg (2001).

\section{Conclusion and implications for evaluators}

If $\mathrm{OM}$ is valued and nurtured through a proper management system (not only in the form of expensive and sophisticated systems, but the memories of individuals) it can enhance the life and working activities of the organisation, its beneficiaries and other stakeholders. The demise of an organisation does not erase its OM. The memory that survives is more than storage bins, but continues to actively influence the surviving beneficiaries and stakeholders. This article illustrates the practical importance of $\mathrm{OM}$ in evaluations. $\mathrm{OM}$ is important for evaluators when considering any type of, or aspect of, evaluation, be it formative, summative, simple, complicated, or complex, and for the evaluation of results or processes of projects, programmes, organisations and networks. To optimise the use of $\mathrm{OM}$ in judgements in evaluations, evaluators should:

- Understand that $\mathrm{OM}$ is important in all monitoring and evaluation activities (from design to disseminating the findings).

- Be aware of the OM and how to access and use it fully.

- Remember that OM differs from human memory, in that the OM contains more than data (experiences, emotions, etc.) and is not always well organised (categorised, filed or stored), accessed or acted upon. The process of forgetting is a more active process than remembering. OM does not deteriorate with age or die with the organisation. 
- Include various time aspects when accessing the OM (including asking questions such as 'when did it happen', 'when are we accessing the information' and 'from when' history).

- Be able to access OM through the most relevant directories.

- Not rely only on explicit (documents) or tacit OM, but use networks, relationships and directories that sometimes are outside the organisation, for example past employees.

- Contribute to the $\mathrm{OM}$ and its wider applications by dissemination of knowledge gained from the evaluation.

- Be aware that the evaluators hold and retain aspects of $\mathrm{OM}$ of all organisations that they have engaged with.

- Take responsibility for their contribution to national, regional, continental and global memory through publications and wider dissemination of results.

- African evaluators, and evaluators working in Africa, should be aware of the differences in accessing OM in the African context, for example the use of narratives and extended individual (non-documented) OM.

\section{Acknowledgements Competing interests}

The author declares that she has no financial or personal relationship(s) that may have inappropriately influenced her in writing this article.

\section{References}

Akgün, A.E., Byrne, J.C., Lynn, G.S. \& Keskin, H., 2007, 'Organizational unlearning as changes in beliefs and routines in organizations', Journal of Organizational Change Management 20(6), 794-812. http://dx.doi.org/10.1108/09534810710831028

Al-Talil, B.B., 2004, Rethinking and NGO: Development, Donors and Civil Society in Jordan, I B Taris, London.

Ammenwerth, E., Iller, C. \& Mansmann, U., 2003, 'Can evaluation studies benefit from triangulation? A case study', International Journal of Medical Information 70(2-3), 237-248. http://dx.doi.org/10.1016/S1386-5056(03)00059-5

Anand, V., Manz, C.C. \& Glick, W.H., 1998, 'An organisational memory approach to information management', Academy of Management Review 23(4), 796-809.

Baddeley, A., 1998, Your memory: A user's guide, Prion, London.

Britton, B., 2005, 'Organisational learning in NGOs: Creating the motive, means and opportunity', Praxis Paper No 3, The International NGO Training and Research Centre (INTRAC).

Burn, J.M. \& Ash, C.G., 2000, 'Managing knowledge in an ERP enabled virtual organisation', in D.G. Schwartz, M. Divitini \& T. Brasethvik (eds.), Internet-based
organizational memory and knowledge management, Idea Group Publishing, organizational memory and knowledge management, Idea
Hershey. http://dx.doi.org/10.4018/978-1-878289-82-7.ch011

Carroll, T.F. \& Montgomery, J.D., 1987, 'Supporting Grassroots Organizations', Monographs 87-1, Lincoln Institute of Land Policy, Cambridge.

Connell, N.A.D., Klein, J.H. \& Powell, P.L., 2003, 'It's tacit knowledge but not as we know it: Redirecting the search for knowledge', Journal of Operational Research Society 54, 140-152. http://dx.doi.org/10.1057/palgrave.jors.2601444

Corbett, J.M., 2000, 'On being an elephant in the age of oblivion computer-based information systems and organisational memory', Information Technology \& People 13(4), 282. http://dx.doi.org/10.1108/09593840010359482

Cousins, J.B. \& Earl, L.M., 1992, 'The Case for Participatory Evaluation' Education Evaluation and Policy Analysis 14(4), 397-418. http://dx.doi org/10.3102/01623737014004397

Curry, M.A., Hassouneh-Phillips, D. \& Johnston-Silverberg, A., 2001, 'Abuse of women with disabilities: An ecological model and review', Violence Against Women 7(1), 60-79. http://dx.doi.org/10.1177/10778010122182307

Edwards, M. \& Fowler, A., 2002, The Earthscan Reader on NGO Management, Earthscan Publications, London.

Funnell, S.C. \& Rogers, P.J., 2011, Purposeful Program Theory, Jossey-Bass, San Francisco, CA.

Girard, J.P., 2009, Building organizational memories: Will you know what you knew?, IGI-Global, Hershey, PA. http://dx.doi.org/10.4018/978-1-59904-540-5
Hall, W.P., 2005, 'Biological nature of knowledge in the learning organisation', The Learning Organisation 12(2), 169-188. http://dx.doi.org/10.1108/09696470510583548

Hamidi, S.R. \& Jusoff, K., 2009, 'The characteristic and success factors of an organizational memory information system', Computer and Information Science 2(1), 142-151.

Henderson, R.M., 1996, 'Technology changes and the management of architectural knowledge', in M.D. Cohen \& L.S. Sproull (eds.), Organizational learning, Sage, Thousand Oaks, CA.

Jansen van Rensburg, M.S., 2004, 'From victim to victory: The experiences of abused women and the salience of the support they encounter', PhD thesis, Dept. of Psychology, University of South Africa.

Jansen van Rensburg, M.S., 2011a, 'Forgetting to Remember: Organisational Memory', $\mathrm{PhD}$ thesis, Dept. of Industrial and Organisational Psychology, University of South Africa.

Jansen van Rensburg, M.S., 2011b, 'Using organizational memory directories to analyze networks', in S. Mathison (ed.), Really new directions in evaluation: Young evaluators' perspectives, New Directions for Evaluation 131, 97-102.

Jashapara, A., 2007, 'Moving beyond tacit and explicit distinctions: a realist theory of organizational knowledge', Journal of Information Science 33(6), 752-766. http:// dx.doi.org/10.1177/0165551506078404

Krippendorff, K., 1975, 'Some principles of information storage and retrieval in society', General Systems, 20 15-35.

Kurtyka, J., 2005, 'A systems theory of business intelligence', Data Management Review, viewed 3 September 2008, from http://www.dmreview.com/ issues/20051201/1042317-1.html

Kurtyka, J., 2009, 'Aligning business intelligence to organization culture', Information Management Special Reports, 17, viewed 15 January 2011, from http://www. information-management.com/specialreports/2009_131/10015066-1.html

Levin, D.Z. \& Cross, R., 2004, 'The strength of weak ties you can trust: The mediating role of trust in effective knowledge transfer', Management Science 50(11), 14771490. http://dx.doi.org/10.1287/mnsc.1030.0136

McNamara, C., 2006, Field guide to consulting and organizational development: A collaborative and systems approach to performance, change and learning (for working with for-profit businesses and government agencies), Authenticity (for working with for-profit business
Consulting LLC, Minneapolis, MN.

Nevo, D., \& Wand, Y., 2005, 'Organizational memory information systems: A transactive memory approach', Decision Support Systems 39(4), 549-562. http://dx.doi.org/10.1016/j.dss.2004.03.002

Organisation for Economic Co-operation and Development (OECD), 2001, Evaluation and AID Effectiveness No 5 - Evaluation Feedback for Effective Learning and Accountability, OECD Publishing.

Patton, M.Q., 2002, Qualitative research and evaluation methods, 3rd edn., Sage, London.

Preskill, H. \& Torres, R.T., 2004, 'The learning dimension of evaluation use', New Directions for Evaluation 2000(88), 25-37. http://dx.doi.org/10.1002/ev.1189

Roth, G. \& Kleiner, A., 1998, 'Developing organizational memory through learning histories', Organizational Dynamics 27(2), 43-60. http://dx.doi.org/10.1016/ S0090-2616(98)90023-7

Russ-Eft, D. \& Preskill, H., 2009, Evaluation in organizations: A systematic approach to enhancing learning, performance, and change, Basic Books, New York.

Sauvagnac, C. \& Falzon, P., 2003, 'Organizational memory: The product of a reflexive activity', International Journal of Cognitive Technology, Special Issue: Cognitive Ergonomics 8(1), 54-60.

Schoeneborn, D.B. \& Blaschke, S., 2009, 'The organization that never sleeps: A metaphorical pathology of organizational insomnia', paper presented at the annual meeting of the International Communication Association, Dresden International Congress Centre, Dresden, viewed on 18 January 2011, from http://www.allacademic.com/meta/p92372 index.html

Schwartz, D.G., Divitini, M. \& Brasethvik, T., 2000, Internet-based organisationa memory and knowledge management, Idea Group Publishing, London.

Searle, J.R., 1999, Mind, language and society: Philosophy in the real world, Basic Books, New York.

Sparrow, P., 1999, 'Strategy and cognition: Understanding the role of management knowledge structures, organizational memory and information overload', Creativity \& Innovative Management 8(2), 140-149, http://dx.doi.org/10.1111/14678691.00128

Stake, R., 1995, The art of case research, Sage Publications, Newbury Park, CA.

Stein, E.W., 1989, 'Organizational memory: Socio-technical framework and empirical research', unpublished PhD thesis, University of Pennsylvania. http://dx.doi. org/10.1016/0268-4012(94)00003-C

Stein, E.W., 1995, 'Organisational memory: Review of concepts and recommendations for management', International Journal of Information Management 15(1), 17-32.

Tarsilla, M., 2010, 'Being blind in a world of multiple perspectives: The evaluator's dilemma between the hope of becoming a team player and the fear of becoming a critical friend with no friends, Journal of Multidisciplinary Evaluation 13(6), 200-205.

United States Agency for International Development (USAID), 2011, USAID evaluation policy, USAID, Washington.

Walsh, J.P. \& Ungson, G.R., 1991, 'Organisational memory', Academy of Management Review 16(1), 57-91.

Watson, R.T., 2006, Data management, databases and organizations, 5th edn., John Wiley, New York. 